\title{
PENGARUH PARTISIPASI KOMITE DAN PENGALOKASIAN DANA TERHADAP PENINGKATAN MUTU PERPUSTAKAAN
}

\author{
Sabriana Oktaviana Gintulangi ${ }^{*}$, I Kadek Satria Arsana ${ }^{2}$ \\ 1,2 Sekolah Tinggi Ilmu Administrasi Bina Taruna Gorontalo, Jl. Jaksa Agung Suprapto No.40, 96115, \\ Limba U Dua, Kota Sel., Kota Gorontalo, Indonesia \\ $1^{*}$ Corresponding Author Email: Sabrianna05@gmail.com
}

\begin{abstract}
This study aims to determine if there is an influence between committee participation and allocation of funds to improve the quality of libraries in SMP N 1 Kabila Kab. Bone Bolango. The focus of the problem of this study is to find out (1) whether there is a positive influence between committee participation and the improvement of the quality of libraries, (2) to find out if there is a positive influence between the allocation of funds to improve the quality of libraries and (3) to find out if there is a significant influence between committee participation and allocation of funds to improve the quality of libraries in SMP N 1 Kabila. The method used in this study was a quantitative method with a sample number of 88 respondents. Instruments used in the form of questionnaires. The population in this study was 807 people consisting of students at SMP 1 Kabila. The sample used is random sampling where sampling is done randomly, regardless of strata or level in the population. Based on the results of the analysis of value data is - $t$ count($1,873)>-t$ table $(-1,992)$ means that committee participation has no effect on improving the quality of libraries. The allocation of funds $t$ calculate $(4,816)>t$ table $(1,992)$ means the allocation of funds positively affects the improvement of the quality of libraries. Testing together for variables $\mathrm{X} 1, \mathrm{X} 2$ and Y $\mathrm{f}$ count $>\mathrm{f}$ table $(12,754>3.10)$ means that committee participation and allocation and library quality improvement have a significant effect.
\end{abstract}

Keywords: Committee Participation, Allocation of Funds, Library Quality

\begin{abstract}
ABSTRAK
Penelitian ini bertujuan untuk mengetahui apakah ada pengaruh antara partisipasi komite dan pengalokasian dana terhadap peningkatan mutu perpustakaan di SMP N 1 Kabila Kab. Bone Bolango. Adapun fokus masalah dari penelitian ini adalah untuk mengetahui (1) apakah ada pengaruh yang positif antara partisipasi komite dengan peningkatan mutu perpustakaan , (2) untuk mengetahui apakah ada pengaruh yang positif antara pengalokasian dana terhadap peningkatan mutu perpustakaan dan (3) untuk mengetahui apakah ada pengaruh yang signifikan antara partisipasi komite dan pengalokasian dana terhadap peningkatan mutu perpustakaan di SMP N 1 Kabila. Metode yang digunakan dalam penelitian ini adalah metode kuantitatif dengan jumlah sampel 88 responden. Instrumen yang digunakan berupa angket. Populasi dalam penelitian ini adalah sebanyak 807 orang yang terdiri dari seluruh siswa Di SMP 1 Kabila. Sampel yang digunakan adalah random sampling dimana pengambilan sample dilakukan secara acak, tanpa memperhatikan strata atau tingkat dalam angota populasi. Berdasarkan hasil analisis data nilai adalah -t hitung $(-1,873)>-t$ tabel $(-1,992)$ artinya parisipasi komite tidak berpengaruh pada peningkatan mutu perpustakaan. Kemudian pengalokasian dana thitung $(4,816)>t$ tabel $(1,992)$ artinya pengalokasian dana berpengaruh positif terhadap peningkatan mutu perpustakaan. Pengujian bersamasama untuk variabel X1, X2 dan Y f hitung $>\mathrm{f}$ tabel $(12,754>3,10)$ artinya antara partisipasi komite dan pengalokasian dana terhadap peningkatan mutu perpustakaan berpengaruh secara signifikan
\end{abstract}

Kata kunci : Partisipasi Komite, Pengalokasian Dana, Mutu Perpustakaan

* Copyright (c) 2021 Sabriana Oktaviana Gintulangi, I Kadek Satria Arsana

This work is licensed under a Creative Commons Attribution-ShareAlike 4.0 International License.

Diterima: 8 Maret 2021; Revisi: 23 Maret 2021 ; Disetujui: 29 Maret 2021 


\section{PENDAHULUAN}

Salah satu masalah dalam dunia pendidikan adalah masalah lemahnya proses pembelajaran (Hidayah, 2015; Suryana, 2020). Sementara menurut Tafsir pendidikan merupakan investasi di bidang sumber daya manusia untuk membangun peradaban serta eksistensi manusia di dunia (Hidayat, 2020), sehingga perlu melakukan upaya peningkatan kualitas pembelajaran. Dalam proses pembelajaran, anak kurang didorong untuk mengembangkan kemampuan berfikir. Proses pembelajaran yang terjadi terpaku hanya di dalam kelas, yaitu proses pembelajaran yang diarahkan kepada kemampuan anak untuk menghafal informasi, otak anak di paksa untuk mengingat dan menimbun berbagai informasi tampa dituntut untuk memahami informasi yang diingatnya itu untuk dihubungkan dengan kehidupan seharihari (Saparwadi, 2016). Tujuan didirikannya perpustakaan adalah untuk menciptakan kegemaran membaca pada siswa. Perpustakaan sekolah adalah tempat awal siswa menikmati fasilitas, dalam menikmati tujuan tersebut belum secara merata bersumbangsi dengan maksimal dan memuaskan. Keadaan ruang yang disebut sebagai perpustakaan berada ditempat terpencil, pengap, berdebu dan tidak memenuhi standar perpustakaan. Bahan perpustakaan yang ada di rak dan yang masih dibungkus plastik ditutupi debu tebal pertanda koleksi tersebut belum atau bahkan tidak terjamah oleh tangan pengelola (Rosinar, 2014).

Anggaran rencana perpustakaan adalah anggaran dari sumbangan wali siswa, serta dapat bantuan dari pemerintah yang alokasinya ada yang diberikan kepada perpustakaan untuk meningkatkan perkembangan perpustakaan. Dalam proses penyusunan perencanaan tersebut, melibatkan kepala sekolah, dewan guru, komite, dan wali siswa. Dalam proses berpikir menentukan usaha-usaha yang akan dilakukan pada masa akan datang untuk memperoleh rencana perpustakaan sekolah dengan sebaikbaiknya. Dana yang diajukan untuk program pengelolaan perpustakaan menggunakan dana bantuan operasional daerah/perda. Besar alokasi dana yang diajukan untuk program rencana perpustakaan selama ini sesuai dengan kebutuhan, sehingga perlu adanya alokasi dana untuk rencana pengelolaan perpustakaan tersebut. Anggaran yang di alokasikan pada perpustakaan ini diambil dari DAK (Dana Alokasi Khusus). DAK ini adalah dana yang bersumber dari Anggaran Pendapatan Belanja Negara (APBN) yang di alokasikan pada daerah tertentu dengan tujuan untuk membantu mendanai kegiatan khusus yang menjadi urusan daerah dan merupakan prioritas nasional. Pengalokasian dana 5\% dari seluruh anggaran sekolah untuk perpustakaan mungkin bisa menjadi belenggu yang sangat terasa memberatkan sekolah diantara dilema penyediaan ruang kelas yang nyaman dan aman bagi siswa dan guru untuk melakukan proses kegiatan belajar mengajar. Akibatnya, banyak sekolah mulai tingkat SD sampai SMA baik umum, madrasah maupun kejuruan tidak mampu menyediakan perpustakaan yang berstandar.

Pendidikan di Indonesia bagian sulawesi tepatnya Provinsi Gorontalo di Kabupaten Bone Bolango Kecamatan Kabila, masih terlihat kurang di perhatikan. Mengapa? Karena masih banyak siswa yang terlihat belum memahami seberapa pentingnya pendidikan. Mereka hanya sekedar mengetahui sekolah saja tidak untuk menjadi apa mereka kedepan nanti. Pendidikan bukan hanya sekedar menerima materi dari seorang pengajar tetapi juga pendidikan harus menggali informasi baik melalui perpustakan, media sosial, surat kabar dan lain-lain. Banyak hal yang akan di temukan siswa jika meraka memasuki ruang perpustakaan yang nyaman dan memiliki fasilitas yang lengkap. Maupun sebaliknya siswa tidak akan menemukan apa-apa jika perpustakaan tidak memiliki kelengakapan layaknya perpustakaan pada umumnya.

Disekolah SMP N 1 Kabila perpustakaan hanya akan digunakan pada saat mata pelajaran Bahasa Indonesia saja. Untuk pengenalan perpustakaan saja hanya pada saat tertentu. Selain itu tata ruang perpustakaan masih belum tertata bagus, karena ruangan, buku-buku dan perlengkapan lainnya 
berpengaruh terhadap keberhasilan penyelanggaraan perpustakaan sekolah. Walaupun ruang yang tersedia sangat luas, buku-buku yang tersedia sangat banyak dan jumlah yang beraneka ragam judulnya, perlengkapan yang tersedia sangat lengkap semuanya kurang berguna apabila tidak ditata atau dikelola dengan sebaik-baiknya. Oleh sebab itu agar penyelenggaran perpustakaan sekolah dapat menunjang pelaksanaan proses belajar mengajar, maka perlu adanya penataan kerja atau pengelolaan perpustakaan, agar mutu perpustakaan menjadi baik (Bafadal, 2015).

Keuangan dan pembiayaan merupakan salah satu sumber daya yang secara langsung menunjang efektifitas dan efisiensi pengelolaan pendidikan (Hakim, 2016). Hal tersebut lebih terasa lagi dalam implementasi manajemen berbasis sekolah, yang menuntut kemampuan sekolah untuk merencanakan, melaksanakan dan mengevaluasi serta mempertanggung jawabkan pengelolaan dana secara transparan kepada masyarakat dan pemerintah (Kaha, 2019). Pengelolaan manajemen berbasis sekolah secara optimal dapat meningkatkan kualitas mutu pendidikan, (Ismail, 2018). Mulyasa menegaskan dalam penyelenggaraan pendidikan, keuangan dan pembiayaan merupakan potensi yang sangat menentukan dan merupakan bagian yang tak terpisahkan dalam kajian manajemen pendidikan (Fitri, 2019). Komponen keuangan dan pembiayaan pada suatu sekolah merupakan komponen produksi yang menentukan terlaksananya kegiatan-kegiatan proses belajar mengajar di sekolah bersama komponenkomponen lain (Afriansyah, 2019). Dengan kata lain setiap kegiatan yang dilakukan sekolah memerlukan biaya, baik itu disadari maupun tidak disadari. Komponen keuangan dan pembiayaan ini perlu dikelola sebaik-baiknya, agar dana yang ada dapat dimanfaatkan secara optimal untuk menunjang tercapainya tujuan Pendidikan (Pratiwi \& Afriansyah, 2020).

Studi dari (Rita, 2017) menunjukkan bahwa partisipasi komite sekolah dalam melaksanakan fungsinya seperti memberikan pertimbangan, memediasi serta pengawasan pelaksanaan pendidikan seperti transparansi anggaran, penyediaan fasilitas sarana dan prasarana termasuk perpustakaan berpengaruh sangat baik, namun dalam meningkatkan mutu kualitas pendidikan masih belum optimal. Strategi meningkatkan mutu kualitas pendidikan seperti yang dijelaskan oleh (Ulum, 2017) dalam penelitiannya yakni salah satunya adalah mengoptimalkan komite sekolah dan tidak kalah penting juga meningkatkan kualitas dan kuantitas fasilitas pendidikan seperti buku-buku yang ada di perpustakaan. Meningkatnya kualitas pendidikan juga didukung oleh faktor penunjang yakni perpustakaan yang lengkap. Sehingga perlu memberikan kepuasan kepada pengguna layanan. Namun untuk melengkapi kebutuhan perpustakaan membutuhkan anggaran yang tidak sedikit. Akan tetapi, alokasi anggaran untuk pendidikan yang cukup besar akan berdampak pada kualitas lulusan menjadi lebih baik. Hal ini sejalan dengan penelitian dari (Asyhab, 2010) menjelaskan bahwa penyediaan anggaran memiliki pengaruh yang baik dan positif dalam meningkatkan kualitas lulus. Baiknya kualitas lulusan secara tidak langsung dipengaruhi oleh tersedianya perpustakaan yang memadai yang dapat membantu penggunanya untuk mendapatkan informasi (Irwiansyah, 2018).

Minimnya kajian yang jelas untuk menggambarkan tentang analisis partisipasi komite dan pengalokasian dana terhadap peningkatan kualitas perpustakaan sehingga penelitian ini diharapkan dapat menambah khazanah keilmuan dibidang pendidikan. Jadi peneliti merumuskan masalah 1) apakah ada pengaruh antara partisipasi komite terhadap peningkatan mutu perpustakaan? 2) apakah ada pengaruh antara pengalokasian dana terhadap peningkatan mutu perpustakaan? 3) apakah ada pengaruh partisipasi komite dan pengalokasian dana terhadap peningkatan mutu perpustakaan? 


\section{METODE PENELITIAN}

Pendekatan penelitian yang diterapkan dalam penelitian ini adalah pendekatan kuantitatif karena pendekatan ini menekankan analisis pada data numerikal (angka) yang diolah dengan metode statistika. Pada dasarnya, pendekatan kuantitatif dilakukan pada penelitian inferensial (dalam rangka pengujian hipotesis) dan menyadarkan kesimpulan hasilnya pada suatu probabilitas kesalahan penolakan hipotesis nihil dengan jenis penelitian korelatif. Jumlah populasi sebanyak 907 siswa. Berdasarkan rumus Slovin dalam Syofian Siregar (2012: 61) sampel yang didapat adalah 88. Pengambilan sample dari anggota populasi diambil secara acak atau random sample tanpa memperhatikan strata atau tingkat dalam anggota populasi. Teknik yang digunakan adalah observasi dan penyebaran angket (kuisoner).

\section{HASIL DAN PEMBAHASAN}

\section{Uji Validitas}

Uji validitas adalah ketepatan atau kecermatan suatu instrumen dalam mengukur apa yang ingin di ukur. Uji validitas dilakukan untuk mengetahui valid atau tidaknya suatu kuesioner. Instrumen yang valid adalah instumen yang benar mampu dalam mengukur variabel yang akan diukur dalam penelitian ini, serta mampu menunjukan tingkat kesesuaian antara konsep penelitian dengan hasil pengukuran perhatikan tabel 1 .

Tabel 1. Uji Validitas

\begin{tabular}{ccccccc}
\hline Soal & $\mathbf{X}_{\mathbf{1}}$ & Status & $\mathbf{X 2}$ & Status & $\mathbf{Y}$ & Status \\
\hline 1 & 0,087 & Tidak valid & $-0,044$ & Tidak valid & 0,511 & Valid \\
2 & 0,314 & Valid & 0,479 & Valid & 0,534 & Valid \\
3 & 0,292 & Valid & 0,675 & Valid & 0,304 & Valid \\
4 & 0,279 & Valid & 0,568 & Valid & 0,448 & Valid \\
5 & 0,334 & Valid & 0,397 & Valid & 0,281 & Valid \\
6 & 0,396 & Valid & 0,775 & Valid & 0,547 & Valid \\
7 & 0,083 & Tidak valid & 0,635 & Valid & 0,526 & Valid \\
8 & 0,451 & Valid & 0,760 & Valid & 0,503 & Valid \\
9 & 0,579 & Valid & 0,359 & Valid & 0,285 & Valid \\
10 & 0,366 & Valid & 0,553 & Valid & 0,615 & Valid \\
11 & 0,474 & Valid & 0,509 & Valid & 0,604 & Valid \\
12 & 0,291 & Valid & 0,604 & Valid & 0,660 & Valid \\
13 & 0,410 & Valid & 0,418 & Valid & 0,629 & Valid \\
14 & 0,387 & Valid & 0,764 & Valid & 0,575 & Valid \\
15 & 0,271 & Valid & 0,740 & Valid & 0,603 & Valid \\
\hline
\end{tabular}

Diketahui $r$ tabel dari $\mathrm{N}=88$ adalah 0,207 artinya jika nilai korelasi diatas $r$ tabel maka dapat disimpulkan bahwa item tersebut valid. Sedangkan jika nilai korelasi kurang dari $r$ tabel, maka item tersebut tidak valid dan harus dibuang atau diperbaiki. Dari tabel koefisien validitas terlihat bahwa pada variabel X1 partisipasi komite dari 15 item angket terdapat 2 item yang tidak valid, item nomor 1 dan item nomor 7. Pada tabel koefisien variabel X2 pengalokasian dana dari 15 item terdapat 1 item yang tidak 
valid, yaitu item nomor 1. Dan tabel terakhir koefisien peningkatan mutu perpustakaan semua angket dinyatakan valid.

\section{Uji reliabilitas}

Metode pengambilan keputusan pada uji reliabilitas menggunakan batasan 0,6 . jika kurang dari 0,6 maka instrumen dikatakan tidak reliabel. Begitu pun sebaliknya jika lebih dari 0,6 maka instrumen dikatakan reliabel perhatikan tabel 2 .

\section{Tabel 2. Realibilitas}

Reliability Statistics

\begin{tabular}{cccccc}
\hline $\begin{array}{c}\text { Cronbach's Alpha } \\
\text { (X1) }\end{array}$ & N of Items & Cronbach's Alpha & N of Items & Cronbach's Alpha & (Y) \\
.497 & 15 & .859 & 15 & .791 & 15 \\
\hline
\end{tabular}

Pada cronbach's alpha untuk variabel $\mathrm{X}_{1}$ partisipasi komite diketahui 0,497 dengan jumlah item sebanyak 15. Karena nilai kurang dari 0,6 maka disimpulkan bahwa instrumen pada partisipasi komite tidak reliabel. Pada cronbach's alpha variabel $\mathrm{X}_{2}$ pengalokasian dana diketahui 0,859 dengan jumlah item sebanyak 15. Karena nilai ini lebih dari 0,6 maka pengalokasian dana adalah reliabel dan baik. Pada cronbach's alpha variabel Y partisipasi mutu perpustakaan 0,791 dengan jumlah item sebanyak 15 . Karena nilai ini lebih dari 0,6 maka dapat disimpulkan bahwa instrumen pada peningkatan mutu perpustakaan adalah reliabel dan dapat diterima.

\section{Uji Normalitas data}

\section{Tabel 3. Tests of Normality}

Tests of Normality

\begin{tabular}{lcccccc}
\hline & \multicolumn{3}{c}{ Kolmogorov-Smirnov ${ }^{\mathrm{a}}$} & \multicolumn{2}{c}{ Shapiro-Wilk } \\
\hline & Statistic & Df & Sig. & Statistic & Df & Sig. \\
partisipasi komite & .105 & 88 & .019 & .980 & 88 & .189 \\
pengalokasian dana & .131 & 88 & .001 & .948 & 88 & .002 \\
mutu perpustakaan & .069 & 88 & $.200^{*}$ & .975 & 88 & .091 \\
\hline
\end{tabular}

a. Lilliefors Significance Correction

*. This is a lower bound of the true significance.

H0: normal Ha: tidak normal

1. Tingkat signifikan $5 \%=0,05$, jika sig kurang dari 0,05 maka Ha diterima

2. Sig partisipasi komite $=0,019<0,05$

3. Sig pengalokasian dana $=0,001<0,05$

4. Sig mutu perpustakaan $=0,200>0,05$

Perhatikan tabel 3, Karena variabel partisipasi komite $<0,05$ maka variabel tersebut tidak berdistribusi normal. Pengalokasian dana $<0,05$ artinya tidak memiliki distrubusi normal, dan mutu perpustakaan $>0.05$ memiliki distribusi data normal. Nilai sig dibagian Kolmogorov-Smirnov dalam tabel 
test of normality, terlihat bahwa variabel partisipasi Komite memiliki data berdistribusi normal. Pada Y juga demikian karena dari grafik normal Q-Q Plot terlihat sebaran data yang berkumpul disekitar garis uji yang mengarah ke kanan atas tidak ada data yang terletak jauh dari sebaran data. Oleh karena itu data tersebut berdistribusi normal.

\section{Analisis deskripsi Hipotesis}

H1: variabel partisipasi komite berpengaruh signifikan terhadap mutu perpustakaan H0: variabel patrisipasi komirte tidak berpengaruh signifikan terhadap mutu perpustakaan H2: variabel pengalokasian dana berpengaruh signifikan terhadap mutu perpustakaan H0: variabel pengalokasian dana tidak berpengaruh signifikan terhadap mutu perpustakaan

Dari data paba tabel 1, 2 dan 3 di atas menunjukan bahwa nilai sig. untuk partisipasi komite 0,064>0,05 maka itu H1 ditolak dan H0 diterima. Artinya variabel partisipasi berpengaruh tidak signifikan terhadap mutu perputakaan. Selanjutnya untuk variabel pengalokasian dana, data di atas menunjukan nilai sig. sebesar $0,000<0,05$ maka dari itu hipotesis diterima. Artinya variabel pengalokasian dana berpengaruh signifikan terhadap mutu perpustakaan. Analisis koefisien determinasi digunakan untuk mengetahui seberapa besar presentasi sumbangan pengaruh variabel indepenen secara besama-sama terhadap variabel dependen. Dari outoput tabel model summary dapat diketahui nilai $\mathrm{R}^{2}$ (Adjusted $\mathrm{R}$ Square) adalah 0,480. Jadi sumbangan pengaruh dari variabel independen yaitu $48 \%$ sedangkan sisanya $52 \%$ di pengaruhi oleh faktor lain.

Pada tabel coefficients menunjukan bahwa nilai sig untuk partisipasi komite 0,064 >0,05 maka hipotesis di tolak. Artinya variabel tidak berpengaruh signifikan terhadap peningkatan mutu perpustakaan. Pada variabel pengalokasian dana data tersebut menunjukan nilai sig. sebesar $0,000<0,05$ maka dari itu hipotesis diterima artinya variabel pengalokasian dana terhadap peningkatan mutu perpustakaan berpengaruh signifikan.

\section{Analisis Uji t}

Uji t digunakan untuk menguji pengaruh variabel independen secara parsial terhadap variabel dependen.

\section{Prosedur pengujian $\mathrm{X}_{1}$ (partisipasi komite)}

1. Menentukan hipotesis nol dan hipotesis alternatif $\mathrm{H}_{0}: \mathrm{X}_{1}=0$ artinya partisipasi komite tidak berpengaruh terhadap peningkatan mutu perpustakaan. $\mathrm{H}_{0}: \mathrm{X}_{1} \neq 0$, artinya partisipasi komite berpengaruh terhadap peningkatan mutu perpustakaan.

2. Taraf signifikan yang di gunakan adalah 0,05

3. Thitung dan $t$ tabel

a. Thitung adalah $-1,873$

b. $\mathrm{T}$ tabel $=0,05 / 2=0.0025$ dengan $\mathrm{df}=\mathrm{n}-\mathrm{k}-1$ atau $88-2-1=85$ (k adalah jumlah variabel independen) di dapat $t$ tabel sebesar 1,992

\section{Pengambilan keputusan}

$\mathrm{T}$ hitung $\leq \mathrm{t}$ tabel atau $-\mathrm{t}$ hitung $\geq-\mathrm{t}$ tabel jadi $\mathrm{H}_{0}$ di terima

Thitung $>\mathrm{t}$ tabel atau $-\mathrm{t}$ hitung $<-\mathrm{t}$ tabel jadi $\mathrm{H}_{0}$ di tolak 
Kesimpulannya setelah diketahui - t hitung $(-1,873)>-t$ tabel $(-1,992)$ jadi hipotesis nol diterima artinya partisipasi komite tidak berpengaruh terhadap peningkatan mutu perpustakaan. Tidak berpengaruh signifikan dikarenakan komite sekolah hanyalah pendukung dalam melaksanakan kegiatan. Komite sekolah yang ada Di SMP N 1 kabila tidak memungut biaya apapun. Selain itu, komite sekolah tidak dikhususkan pada kualitas mutu perpustakaan akan tetapi mereka mendukung adanya peningkatan mutu perperpustakaan. Pada penyebaran data partisipasi komite hanya $14,5 \%$ saja nilai yang didapat artinya komite sekolah sudah melakukan tugasnya dengan benar akan tetapi untuk berpengurah terhadap mutu perpustakaan masih sangat rendah.

\section{Prosedur pengujian $X_{2}$}

Thitung adalah 4,816

$\mathrm{T}$ tabel caranya masih sama dengan yang di jelaskan sebelumnya pada prosedur pengujian $\mathrm{X}_{1}$. Jadi $t$ tabel 1,992

\section{Pengambilan keputusan}

T hitung $\leq \mathrm{t}$ tabel atau $-\mathrm{t}$ hitung $\geq-\mathrm{t}$ tabel jadi $\mathrm{H}_{0}$ diterima

Thitung $>\mathrm{t}$ tabel atau $-\mathrm{t}$ hitung $<-\mathrm{t}$ tabel jadi $\mathrm{H}_{0}$ ditolak

Kesimpulannya di ketahui bahwa thitung $(4,816)>t$ tabel $(1,992)$ jadi hipotesis nol ditolak artinya pengalokasian dana berpengaruh terhadap peningkatan mutu perpustakaan. Nilai koefisiean dan thitung adalah positif sehingga pengalokasian dana berpengaruh positif terhadap peningkatan mutu perpustakaan. Tingakat pengaruh untuk pengalokasian dana adalah $44,6 \%$ artinya pengalokasian dana tepat sasaran dan penggunaanya efektif dan efisien dilihat dari tingkat korelasinya cukup kuat. Dengan ini tujuanya akan terwujud dengan semestinya. Pada dasarnya pengaloksian dana ini semua dana yang masuk sesuai dengan pengelolaaanya, sehingga untuk meningkatkan mutu perpustakaan mendapat porsinya sendiri dengan anggaran yang ditetapkan. Alokasi dana sendiri berasal dari dana rutin yang berasal dari Pemda (pemerintah daerah) dan dan BOS (Bantuan Operasional Sekolah).

\section{Analisis Uji f}

1. Ho : tidak pengaruh secara signifikan antara partisipasi komite dan pengalokasian dana terhadap mutu perpustakaan.

2. Ha : ada pengaruh signifikan antara partisipasi komite dan pengalokasian dana terhadap mutu perpustakaan.

3. Tingkat signifikan a $=5 \%$ (signifikan $5 \%$ atau 0.05 adalah ukuran standar yang sering digunakan)

4. F hitung $=12,754$

5. Menentukan $\mathrm{F}$ tabel dengan menggunakan tingkat keyakinan $95 \%$, $\mathrm{a}=5 \%$, df 1 (jumlah variabel- 1 ) $=$ 2, dan df 2 (n-k-1) atau 88-2-1=85. Hasil diperoleh untuk F tabel sebesar 3,10.

6. Kriteria pengujian

7. Ho diterima bila $\mathrm{F}$ hitung $<\mathrm{F}$ tabel $\mathrm{H}_{0}$ diterima

8. Ho ditolak bila $\mathrm{F}$ hitung $>\mathrm{F}$ tabel $\mathrm{H}_{0}$ ditolak

9. Membandingkan F hitung dengan F tabel. Nilai F hitung $>\mathrm{F}$ tabel $(12,754>3.10)$, jadi Ho ditolak.

10. Kesimpulan

Karena, F hitung > F tabel, maka Ho ditolak artinya ada pengaruh secara signifikan antara partisipasi komite dan pengalokasian dana secara bersama-sama terhadap mutu perpustakaan. Jadi dari 
Khazanah Pendidikan Islam, Vol. 3 No. 2: 105 - 113

Pengaruh Partisipasi Komite dan Pengalokasian Dana terhadap Peningkatan Mutu Perpustakaan Sabriana Oktaviana Gintulangi, I Kadek Satria Arsana

kasus ini dapat disimpulakan bahwa partisipasi komite dan pengalokasian dana secara bersam-sama berpengaruh terhadap mutu perpustakaan.

\section{SIMPULAN}

Tidak terdapat pengaruh yang signifikan partisipasi komite terhadap peningkatan mutu perpustakaan. Tidak berpengaruh signifikan dikarenakan komite sekolah hanyalah pendukung dalam melaksanakan kegiatan. Komite sekolah yang ada Di SMP N 1 kabila tidak memungut biaya apapun. Terdapat Pengaruh yang signifikan pengalokasian dana berpengaruh terhadap peningkatan mutu perpustakaan. Tingkat pengaruh untuk pengalokasian dana adalah 44,6\% artinya pengalokasian dana tepat sasaran dan penggunaanya efektif dan efisien dilihat dari tingkat korelasinya cukup kuat. Terdapat pengaruh yang signifikan secara bersamaan antara partisipasi komite dan pengalokasian dana secara bersama-sama terhadap mutu perpustakaan. Implikasi penelitian ini diharapkan dengan meningkatkan kontribusi partisipasi komite sekolah hendaknya lembaga atau sekolah meningkatkan kerjasama dengan komite sekolah khususnya pada proses layanan mutu agar tujuan program yang telah direncankan terlaksana dengan baik. Menumbuh kembangkan peran komite sekolah dalam setiap program pendidikan harus menjadi perhatian khusus dari seluruh warga sekolah, atau satuan pendidikan karena dapat diakui perannya dapat memberikan kontribusi dalam peningkatan mutu sesuai dengan tugas dan fungsinya dalam pendidikan. Komite sekolah adalah bagian dari orang tua murid, sehingga komite sekolah juga memiliki pekerjaan atau kepentingan masing-masing selain sebagai stake holder sekolah, hal ini menyebabkan komite sekolah kurang memiliki waktu yang memadai untuk secara khusus berpartisipasi dalam meningkatkan mutu sekolah.

\section{DAFTAR PUSTAKA}

Afriansyah, H. (2019). Administrasi dan supervisi pendidikan. INA-Rxiv. https://doi.org/10.31227/osf.io/wj9pa

Asyhab, K. S. (2010). Pengaruh Alokasi Anggran Pendidikan, Kualitas Guru Terhadap Tingkat Kelulusan Pendidikan Dasar dan Menengah studi Empiris pada Propinsi Jawa Tengah. Universitas Gadjah Mada.

Bafadal, I. (2015). Pengelolaan Perpustakaan Sekolah. Bumi Aksara.

Fitri, A. (2019). Manajemen Kepala Sekolah dalam Pengelolaan Dana Bantuan Operasional Sekolah (Bos) pada Smp Negeri di Kota Banda Aceh. Jurnal Administrasi Pendidikan: Program Pascasarjana Unsyiah, 7(1).

Hakim, M. N. (2016). Implementasi Manajemen Berbasis Sekolah Dalam Mewujudkan Sekolah Islam Unggulan. Nidhomul Haq: Jurnal Manajemen Pendidikan Islam, 1(2), 104-114. https://doi.org/10.31538/ndh.v1i2.7

Hidayah, N. (2015). Pembelajaran tematik integratif di Sekolah Dasar. Terampil: Jurnal Pendidikan Dan Pembelajaran Dasar, 2(1), 34-49. https://doi.org/10.24042/terampil.v2i1.1280

Hidayat, I. (2020). Kompetensi Guru dalam Pembelajaran PAI berbasis Higher Order Thinking Skills (HOTS) di Sekolah Menengah Pertama. Khazanah Pendidikan Islam, 2(2), 52-67.

Irwiansyah, M. B. (2018). Hubungan tingkat kualitas pelayanan dengan tingkat minat baca di perpustakaan UMG pada mahasiswa. PSIKOSAINS (Jurnal Penelitian Dan Pemikiran Psikologi), 10(2), 105-116.

Ismail, F. (2018). Manajemen Berbasis Sekolah: Solusi Peningkatan Kcalitas Pendidikan. Jurnal Ilmiah Iqra', 2(2). https://doi.org/10.30984/jii.v2i2.541 
Kaha, Y. L. (2019). Evaluasi Program Pendidikan Kelas Khusus Olahraga Pada Sekolah Dasar Inpres Mewet Flores Timur Genap 2017/2018. Jurnal Ilmiah Mandala Education, 5(1), 64-71. https://doi.org/10.36312/jime.v5i1.658

Pratiwi, D., \& Afriansyah, H. (2020). Administrasi Keuangan. https://doi.org/10.31219/osf.io/u2z6r

Rita, H. (2017). Peran Komite dalam Penyelenggaraan Pendidikan di Madrasah Tsanawiyah Negeri 1 Palembang (Studi Manajemen Peningkatan Mutu Berbasis Sekolah). Conciencia, 17(1), 70-80. https://doi.org/10.19109/conciencia.v17i1.1583

Rosinar, E. (2014). Kiat-Kiat Pemberdayaan Perpustakaan Sekolah. Edulib, 4(1). https://doi.org/10.17509/edulib.v4i1.1174

Saparwadi, L. (2016). Efektivitas metode pembelajaran drill dengan pendekatan peer teaching ditinjau dari minat dan prestasi belajar matematika siswa. Jurnal Didaktik Matematika, $3(1), 39-46$.

Suryana, S. (2020). Permasalahan mutu pendidikan dalam perspektif pembangunan pendidikan. Edukasi, 14(1).

Ulum, M. (2017). Strategi peningkatan mutu Sekolah Menengah Kejuruan pasca penerapan sistem manajemen mutu ISO 9001: 2008. Jurnal Pendidikan Ilmu Sosial, 27(1), 69-91. https://doi.org/10.2317/jpis.v27i1.5122 